Article

\title{
Phenotyping, Genotyping, and Selections within Italian Local Landraces of Romanesco Globe Artichoke
}

\author{
Paola Crinò ${ }^{1}$ and Mario Augusto Pagnotta ${ }^{2, *}$ \\ 1 Italian National Agency for New Technologies, Energy and Sustainable Economic Development (ENEA), \\ C.R. Casaccia, Biotechnologies and Agroindustry Division, Via Anguillarese 301, 00123 Roma, Italy; \\ paola.crino@enea.it \\ 2 Department of Agricultural and Forestry Sciences (DAFNE), Università degli Studi della Tuscia, \\ Via S.C. de Lellis, 01100 Viterbo, Italy \\ * Correspondence: pagnotta@unitus.it; Tel.: +39-0761-357-423
}

Academic Editor: Michael Wink

Received: 25 November 2016; Accepted: 23 February 2017; Published: 1 March 2017

\begin{abstract}
Ten Italian globe artichoke clones belonging to the Romanesco typology were characterized in the western coastal area of Italy (Cerveteri, Rome), using a combination of morphological (UPOV descriptors), biochemical (HPLC analysis), and molecular (AFLP, ISSR, and SSR markers) traits. Significant differences among clones were found for many of the quantitative and qualitative morphological traits. Multivariate analyses (Principal Component Analysis) showed that, of the 47 morphological descriptors assessed, four (i.e., plant height, central flower-head weight, earliness, and total flower-head weight) presented a clear grouping of the clones. Biochemical analyses showed that the clones significantly differed in the polyphenolic profiles of the flower-head, with the suggestion that some of these, such as S2, S3, S5, and S18, are more suitable for the fresh market. The clones, clustered by a UPGMA dendrogram based on 393 polymorphic AFLP and ISSR loci, showed that the clones were genetically separated from each other. This highlights the importance of characterizing, evaluating, and conserving autochthonous germplasm for future plant breeding activities. Overall, these studies resulted in the identification of two new clones, selected on the basis of flower-head morphology and earliness. These clones, named Michelangelo and Raffaello, are registered on the Italian National Register of Varieties (DM n. 6135, 3/29/2013 G.U. 91, 18 April 2013).
\end{abstract}

Keywords: Cynara cardunculus; genetic diversity; germplasm selection; nutraceutical compounds; varietal release

\section{Introduction}

The globe artichoke [Cynara cardunculus L. var. scolymus (L.) Fiori] is a diploid species $(2 n=2 x=34)$, traditionally grown for its immature flower-heads and used in dishes across the Mediterranean region [1,2]. More recently, the globe artichoke has also attracted attention due to its potential as a biomass crop [3,4] and for its nutraceutical content [5,6]. As of 2013, global artichoke production was $1793 \mathrm{Mt}$ of heads over an area of 130,676 ha [7]. The top producers were Italy (548 kt/46,954 ha), Egypt (391 kt/16,213 ha), and Spain (200 kt/15,400 ha) [7].

In Italy, the globe artichoke is an economically important horticultural crop, especially in regions such as Sicily (165 Mt/14,832 ha), Apulia (148 Mt/15,610 ha), and Sardinia (114 Mt/13,528 ha) [8]. Italy also houses the richest collections of globe artichoke autochthonous germplasm; the primary cultivated gene pool [9] including farmer varieties/landraces, traditionally propagated vegetatively via offshoots. This cultivated germplasm was traditionally differentiated on the basis of head morphology (Romaneschi, Violetti, Catanesi, Spinosi) [10] or head appearance, and harvest time (autumn and 
spring, or "re-bloom" and "spring" flowering types) [11,12]. Many traditional landraces, however, do not fall into these broad varietal group traits.

Italian production is mainly based on local heterogeneous genotypes, which represent examples of farmer selection carried out on-farm, and are named based on the geographical area of cultivation, without genetic or origin identification [13]. For example, in the Latium region, the Romanesco landraces Castellammare and Campagnano were widely cultivated in non-specialized small-holdings. In 2002, these landraces were added to the PGI (Protected Geographical Indication) 'Romanesco Artichoke of Latium' (Reg. EC n. 2006/2002), the varietal registration platform. Despite the added value of this certification, and the highly sought-after quality of the heads, preferred for traditional recipes, these landraces are being rapidly replaced by new micropropagated artichoke cultivars and seed-propagated F1 hybrids, which are more productive and mature earlier, as the market requests [14]. In particular, the clone C3, derived from the traditional population Castellammare, and selected for its earliness in the Latium region, is widely cultivated [15]. This has led to a significant erosion of Castellammare populations and a corresponding loss of diversity [16]. The traditional Romanesco germplasm contains high levels of genetic variation within each landrace [13,17-21]. Many of these landraces are highly resistant to endemic diseases, such as the Artichoke latent Virus (ArLV) and Verticillium dahliae Kleb. [14,18]. This highlights the importance of conserving the landraces, as their high levels of heterogeneity allow them to respond to abiotic and biotic stresses and adapt to low-input farming systems.

In Italy, more in-depth studies are needed for the genetic improvement of these traditional landraces of Romanesco types, especially in terms of varietal release. Preliminary studies on the characterization of traditional Romanesco genetic resources have assessed the complementarity between molecular and morphological approaches [16,18,22]. However, plant breeding programs aimed at the recovery and release of new Romanesco registered varieties have not been carried out. Indeed, in Italy, it is mainly the seed-propagated F1 hybrids (SIAN code/Hybrid name: 3062/Ademaro, 3284/Almiro, 3061/Amos, 3285/Ernesto, 3058/Istar, 3064/Napoleone, 3300/Omero, 3066/Rinaldo, 3282/Romano, 3283/Verdiano, and 3059/Zenone) that have been placed on the National Register of Horticultural Varieties of Italian Ministry of Agriculture, Food and Forestry Policies (Commission Directive 2006/124/EC).

Taking into account the above issues and the requirements for several well-defined quality standards for the release of new varieties (European Directive No. 184/1/2004), autochthonous germplasm belonging to the Romanesco typology was evaluated for two years [18], within the framework of the CYNARES project (financial support from the European Commission, DG for Agriculture and Rural Development, under Council Regulation EC No 870/2004).

The same genetic material was assessed: (i) molecularly, utilizing ISSR, AFLP, and SSR markers; (ii) morphologically, through the use of UPOV (International Union for the Protection of New Varieties of Plants) descriptors; and (iii) biochemically, using HPLC analysis. The objectives were to: (a) investigate the existing genetic diversity within and among these clones under morphological, biochemical, and molecular profiles; and (b) select clones for varietal release and inclusion on the Italian Register of National Varieties.

\section{Materials and Methods}

\subsection{Experimental Field and Plant Material}

Ten clones, selected on the basis of previous data [18], and representative of Romanesco germplasm, were assessed in this study. In particular, clones from the north and south of Rome (Figure 1), with different times of heading, were used. The clones S17, S22, and S23 were early heading specimens; S18, S20, and S21 were medium heading specimens; and S2, S3, S5, and S11 were late heading specimens. All clones were planted in Cerveteri, Latium (Italy) $\left(41^{\circ} 59^{\prime} \mathrm{N} 12^{\circ} 01^{\prime} \mathrm{E} 30 \mathrm{~m}\right.$ a.s.l.), in an experimental farm station belonging to the Regional Agency for the Development and 
the Innovation of Agriculture (ARSIAL), where they were evaluated for two subsequent growing seasons. Landraces were planted in a randomized block design with four replicates, with each test plot consisting of twenty plants. The planting density was 7700 plants.ha $^{-1}$ (inter and intra-row distances of 1.30 and $1.00 \mathrm{~m}$, respectively). Field experiments were conducted under low resource inputs (one irrigation/year in August consisting of $60 \mathrm{~mm}$ of water, organic fertilization with $50 \mathrm{~kg}$ of $\mathrm{N} \cdot \mathrm{ha}^{-1}$, and without herbicides and gibberellic acid), as per local agronomical practices. During the trials, meteorological data were collected by a meteorological station set up at the experimental farm. The first growing season exhibited maximum and minimum air temperatures (expressed as average values) ranging from 30.6 to $4.8^{\circ} \mathrm{C}$ between August and May, while temperatures over the second growing season ranged from 29.1 to $5.9^{\circ} \mathrm{C}$. The recorded value for rainfall was $549.6 \mathrm{~mm}$ from August to May of the first year of the assessment, and $921.8 \mathrm{~mm}$ in the second year. Soil characteristics were as follows: $62 \%$ sand, $23 \%$ clay, and $15 \%$ silt; $\mathrm{pH} 6.3$; organic matter, $1.24 \%$; total nitrogen, $0.08 \%$; $\mathrm{P}$, $24 \mathrm{ppm}$; K, 355 ppm; and CE, $0.16 \mathrm{mS}$.

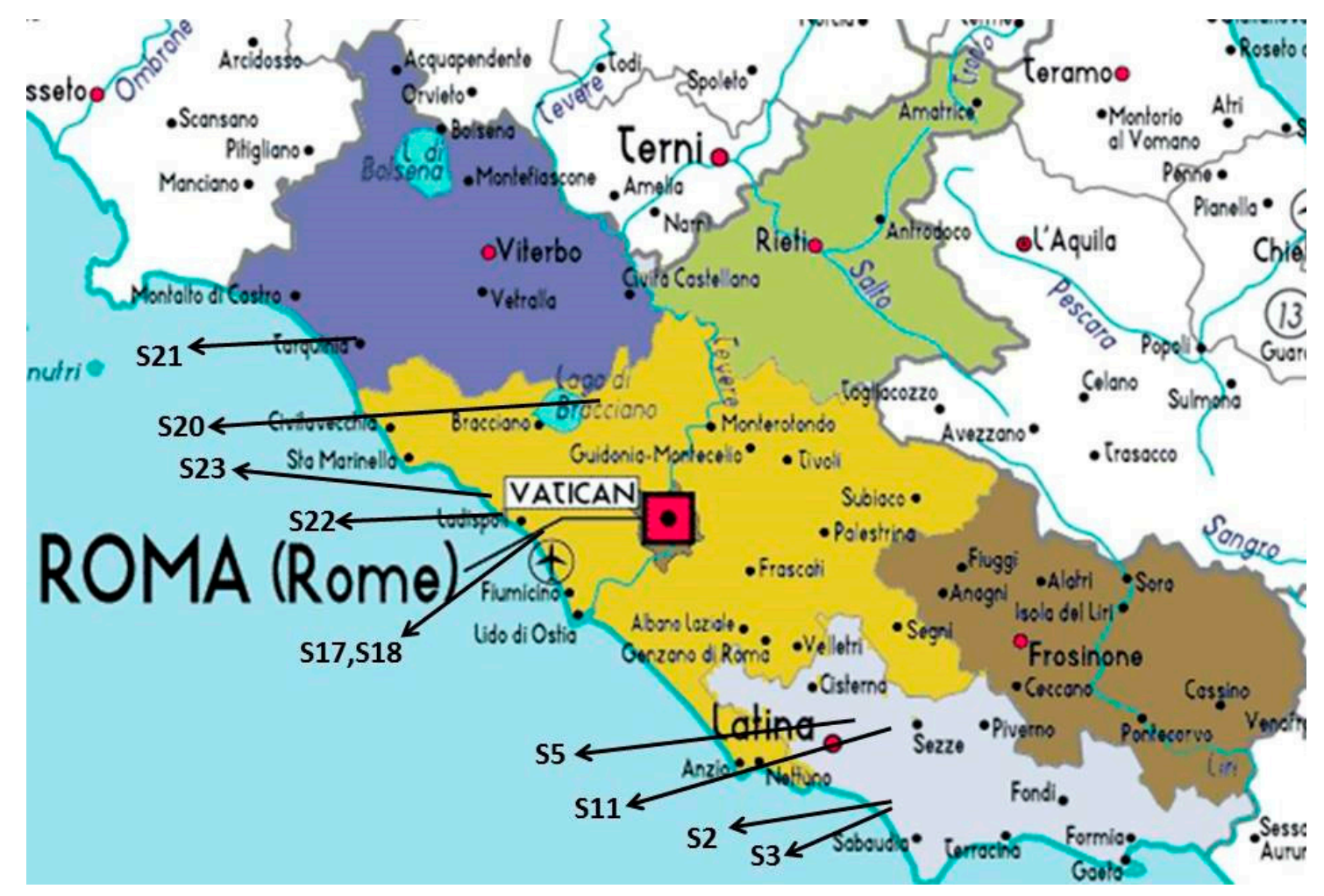

Figure 1. Geographic location of the analyzed clones.

\subsection{Morphological Analysis}

Twelve plants per clone (three plants per replicate) were randomly selected in the center of the plot and assessed agro-morphologically. Each plant was phenotyped using standard UPOV descriptors for the globe artichoke, along with another well-defined group of complementary Romanesco type descriptors $[18,22,23]$. The assessment utilized 47 agro-morphological descriptors, described in Table 1 , were recorded either one or twice a week between February and May, in both growing seasons. 
Table 1. Forty-seven morphological descriptors utilized for clone characterization.

\begin{tabular}{|c|c|c|c|}
\hline No. & Descriptor & No. & Descriptor \\
\hline 1. & Plant: height (including central flower-head) & 25. & Central flower-head: shape of tip \\
\hline 2. & Plant: number of lateral shoots on main stem & 26. & First flower-head on lateral shoot: length \\
\hline 3. & Main stem: height (excluding central flower-head) & 27. & First flower-head on lateral shoot: diameter \\
\hline 4. & $\begin{array}{l}\text { Main stem: distance between central flower-head and } \\
\text { youngest well developed leaf }\end{array}$ & 28. & First flower-head on lateral shoot: size \\
\hline 5. & $\begin{array}{l}\text { Main stem: diameter (at about } 10 \mathrm{~cm} \text { below central } \\
\text { flower-head) }\end{array}$ & 29. & First flower-head on lateral shoot: shape \\
\hline 6. & Leaf: attitude & 30. & Outer bract: length of base \\
\hline 7. & Leaf: long spines & 31. & Outer bract: width of base \\
\hline 8. & Leaf: length & 32. & Outer bract: thickness at base \\
\hline 9. & Leaf: incisions & 33. & Outer bract: main shape \\
\hline 10. & Leaf: number of lobes, & 34. & Outer bract: shape of apex \\
\hline 11. & Lobe: shape of tip (excluding terminal lobe) & 35. & Outer bract: depth of emargination \\
\hline 12. & Lobe: number of secondary lobes & 36. & Outer bract: colour (external side) \\
\hline 13. & Lobe: shape of tip of secondary lobes & 37. & Outer bract: hue of secondary colour \\
\hline 14. & Leaf blade: shape in cross section & 38. & Outer bract: size of spine \\
\hline 15. & Leaf blade: intensity of green colour & 39. & Outer bract: mucron \\
\hline 16. & Leaf blade: hue of green colour & 40. & $\begin{array}{l}\text { Central flower-head: anthocyanin coloration of inner } \\
\text { bracts }\end{array}$ \\
\hline 17. & Leaf blade: intensity of grey hue & 41. & Central flower-head: density of inner bracts \\
\hline 18. & Leaf: hairiness on upper side & 42. & Receptacle: diameter \\
\hline 19. & Leaf blade: blistering & 43. & Receptacle: thickness \\
\hline 20. & Petiole: anthocyanin coloration at base & 44. & Receptacle: shape in longitudinal \\
\hline 21. & Central flower-head: length & 45. & Main head weight \\
\hline 22. & Central flower-head: diameter & 46. & Total number of heads \\
\hline 23. & Central flower-head: size & 47. & Main Head date of maturity \\
\hline 24. & Central flower-head: shape in longitudinal section & & \\
\hline
\end{tabular}

\subsection{DNA Extraction and Molecular Marker Analysis}

One plant per landrace was randomly selected and molecularly assessed. The total genomic DNA was isolated from young leaves and extracted from $100 \mathrm{mg}$ of frozen tissue, using the Plant DNA Extraction Kit (EURx Ltd. 80-297 Gdansk Poland). The DNA quality was checked by electrophoresis in a $1 \%$ agarose gel and stained with ethidium bromide. The DNA concentration was determined through spectrophotometry.

Molecular analysis was run using AFLPs, ISSRs, and SSRs markers.

Seven AFLP primer combinations were used: EcoACC/MseCTA, EcoACG/MseCTT, EcoAGC/MseCTT, MseAC/PstCA, MseAC/PstCG, MseGC/PstCA, and MseGC/PstCG. Amplifications were carried out according to Vos et al. [24], and consisted of using MseI and PstI to digest the template DNA. Non-selective primers were used for pre-amplification. Four ISSR primers, selected from the British Columbia University (810, 834, 841, and 857), were also used. PCR reactions were performed in a final volume of $10 \mu \mathrm{L}$, containing $10 \mathrm{ng}$ DNA, $0.3 \mu \mathrm{M}$ primer, $100 \mu \mathrm{M}$ dNTP, $10 \mathrm{mM}$ Tris- $\mathrm{HCl}$ ( $\mathrm{pH}$ 9.0), and 1 Unit of Taq polymerase. The amplification regime was $94{ }^{\circ} \mathrm{C} / 5 \mathrm{~min}$, followed by 39 cycles of $96^{\circ} \mathrm{C} / 1 \mathrm{~min}, 43-54{ }^{\circ} \mathrm{C} / 1 \mathrm{~min}$ (see Ta in Table 2), and $72{ }^{\circ} \mathrm{C} / 2 \mathrm{~min}$, ending with an extension step of $72{ }^{\circ} \mathrm{C} / 10 \mathrm{~min}$.

Thirteen SSR primers, developed by Acquadro et al. [25] (CMAL11, CMAL117, CMAL24, CMAL06, and CMAL108), [26] (CDAT01, CLIB02, and CLIB12), [27] (CMAFLP18), and Sonnante et al. [28] (CsPal03, CsPal02, CsEST03, and CsCiCaCa05), were used. Primers, sequences, and their amplification conditions were selected in accordance with the authors who developed the primers (see above); the annealing temperatures are reported in Table 2.

The forward primers for all of the 24 markers were labeled with either FAM or HEX. PCR amplifications were resolved in a 3130xl sequencer machine (Applied Biosystems, Foster City, CA, USA) and read by Genemap 3.1. Software (Applied Biosystems). Primer reproducibility was checked by repeating the amplifications twice. 
Table 2. ISSR, AFLP, and SSR used for germplasm characterization.

\begin{tabular}{|c|c|c|c|c|c|c|}
\hline \multicolumn{2}{|c|}{ Molecular Markers } & Ta & NPB & $\mathrm{He}$ & Ho & PIC \\
\hline \multirow{7}{*}{ AFLP } & EcoACC/MseCTA & & 5 & 0.37 & & \\
\hline & EcoACG/MseCTT & & 3 & 0.45 & & \\
\hline & EcoAGC/MseCTT & & 4 & 0.34 & & \\
\hline & MseAC/PstCA & & 81 & 0.31 & & \\
\hline & MseAC/PstCG & & 68 & 0.27 & & \\
\hline & MseGC/PstCA & & 95 & 0.28 & & \\
\hline & MseGC/PstCG & & 67 & 0.28 & & \\
\hline \multirow{4}{*}{ ISSR } & $810(\mathrm{GA})_{8} \mathrm{~T}$ & 43 & 4 & 0.24 & & \\
\hline & $827(\mathrm{AG})_{8} \mathrm{G}$ & 52 & 1 & 0.41 & & \\
\hline & $841(\mathrm{GA})_{8} \mathrm{YC}$ & 45 & 30 & 0.20 & & \\
\hline & $857(\mathrm{AC})_{8} \mathrm{YG}$ & 54 & 35 & 0.22 & & \\
\hline \multirow{13}{*}{ SSR } & CMAL11 & 54 & 2 & 0.32 & 0.40 & 0.268 \\
\hline & CMAL117 & 60 & 2 & 0.48 & 0.60 & 0.365 \\
\hline & CMAL24 & 60 & 4 & 0.66 & 0.90 & 0.592 \\
\hline & CMAL06 & 60 & 2 & 0.50 & 0.80 & 0.375 \\
\hline & CMAL108 & 60 & 2 & 0.10 & 0.10 & 0.091 \\
\hline & CDAT01 & 54 & 3 & 0.56 & 1.00 & 0.442 \\
\hline & CLIB02 & 59 & 2 & 0.50 & 0.90 & 0.373 \\
\hline & CLIB12 & 55 & 2 & 0.50 & 0.90 & 0.373 \\
\hline & CMAFLP18 & 55 & 2 & 0.50 & 0.90 & 0.373 \\
\hline & CsPal03 & 52 & 3 & 0.55 & 1.00 & 0.442 \\
\hline & CsPal02 & 60 & 2 & 0.10 & 0.10 & 0.091 \\
\hline & CsEST03 & 62 & 2 & 0.38 & 0.50 & 0.305 \\
\hline & CsCiCaCa05 & 55 & 2 & 0.10 & 0.10 & 0.091 \\
\hline
\end{tabular}

Ta: annealing temperature; NPB: number of polymorphic bands; He: expected heterozygosity; Ho: observed heterozygosity; PIC: polymorphic information content.

\subsection{Biochemical Analysis}

\subsubsection{Solvents and Reagents}

Ethanol solvent and reagent grade formic acid (96\%) were purchased from Scharlau Co. (Barcelona, Spain). Deionized water was made using a Milli-Q water purifying system, purchased from Millipore Co. (Bedford, MA, USA). Apigenin, luteolin, luteolin-7-O-glucoside (cynaroside), 1,3-O-dicaffeoylquinic acid (cynarin), and 1,5-O-dicaffeoylquinic acid were obtained from Extrasynthese (Lyon, France); while 3-O-caffeoylquinic acid (chlorogenic acid) was obtained from Sigma Chemical Co. (St. Louise, MO, USA).

\subsubsection{Polyphenol Extraction and HPLC Analysis}

At least three primary flower-heads per replicate were harvested during the commercial maturation stage for each clone, in the spring of the first growing season. All samples were immediately weighed, freeze-dried, and grounded to a $1 \mathrm{~mm}$ diameter fine powder. Extraction was performed using Accelerated Solvent Extraction (ASE), according to the methods described by Ciancolini et al. [6].

Polyphenol analysis was carried out using a Dionex HPLC chromatograph, equipped with an UV detector HP 1100. HPLC separation was performed as previously described by Ciancolini et al. [6]. Chromatograms were recorded at $325 \mathrm{~nm}$ for chlorogenic acid, 1,3-O-dicaffeoylquinic acid, and 1,5-O-dicaffeoylquinic acid, and at $350 \mathrm{~nm}$ for luteolin, apigenin, and cynaroside. All samples were analyzed in duplicate.

\subsection{Statistical Analysis}

Morphological and biochemical data were analyzed through an ANOVA running Generalized Linear Model (GLM), Principal Component Analysis (PCA), and Cluster analyses using SPSS software 
version 15.0. Mean separations were performed by a Tukey test. Significance was accepted at $p \leq 0.05$ level. Shapiro-Wilk and Kurtosis tests were used to assess the normality of the observations. Based on the morphological traits, a similarity dendrogram was constructed using an agglomerative hierarchical cluster analysis.

Polymorphic bands for each ISSR and AFLP marker (between 50 and $500 \mathrm{bp}$ ) were recorded; each significant peak was assumed to represent a single locus, with two possible alleles (presence and absence). Profiles were converted to a 1/0 matrix for statistical analyses, while band dimensions were considered for SSR markers. Statistics of the molecular data, such as number of polymorphic bands (NPB), expected heterozygosity (He), observed heterozygosity (Ho), and polymorphic information content (PIC), were computed for each clone, in accordance with Pagnotta et al. [29], utilizing GenAlEx [30] or Power Marker [31]. The marker matrix was also used to compute Nei's genetic distances [32] between clones, and then used to conduct a cluster analysis and to draw an UPGMA diagram.

The numbers of common versus rare alleles were also analyzed to obtain an assessment of the richness within each landrace. Rare alleles were categorized as those alleles present in less than $5 \%$ of each landrace.

A Mantel test was applied to verify the statistical relationship between the distance matrices obtained by the genetic and morphological traits [33], as well as between biochemical and morphological matrices. A Pearson's correlation was used to evaluate the Mantel test (significance level of $p \leq 0.05)$.

\section{Results}

\subsection{Morphological Characterization}

On the basis of morphological data, a cluster analysis was applied and a similarity dendrogram was generated (Figure 2), which showed significant differences among clones. The dendrogram obtained allocated the 10 clones into two main clusters: the first cluster grouped the clones S2, S3, S5, and S11; and the clones S17, S20, S18, S22, S23, and S21 were included in the second group. In the two identified clusters, the clones were mainly divided on the basis of their earliness/lateness and geographical origin (south vs. north of Rome, see Figure 1). This is consistent over the two years (data unshown), although eight out of the 15 traits have significant clone-by-year interactions (Table 3).

For 15 of the 47 quantitative and qualitative traits measured, significant differences among clones were found, highlighting high levels of genetic variability within the germplasm (Table 3). With reference to morphological traits, S5, S18, and S20 showed the highest values for plant height. The clones S3, S11, S18, S20, and S21 exhibited the longest distance between the youngest leaf on the main floral stem and the central flower-head. S11, S17, S18, S22, and S23 revealed the biggest main floral stem diameter. The clones S2, S17, and S23 were characterized by the shortest head length, while S3, S17, S18, and S20 had the smallest head diameter. Regarding the head shape, S20 showed the most elongated heads, while S2, S17, S22, and S23 provided the most elliptical heads. Concerning the head color, the clones S11, S18, and S21 showed the most intense purple-colored striped heads, while S5, S17, S22, and S23 were characterized by the most green-colored heads. In both growing seasons, S17 budded the earliest with regard to the appearance of the central flower-head, while S2, S3, S5, and S11 produced their central flower-heads later. The highest value for the number of total heads produced was seen for S22, and S23, S17, S21, S22, and S23 yielded the highest values when expressed as $\mathrm{kg}$ of heads per plant (Table 3). The ANOVA test revealed significant differences between years for 13 traits and significant clone-per-year interactions for eight traits out of the 15 traits, showing significant differences among clones (Table 3). The principal component analysis undertaken, based on the morphological datasets of clones of the same typology, showed that only $37.61 \%$ of the total variance is explained by the first three components (Figure 3). Nevertheless, the first PC factor ( $15.84 \%$ of variance) included the following primary traits: plant height, main floral stem height, head 
shape index, receptacle shape, time of the central flower-head appearance, and time of the primary flower-head appearance. The second factor explained $13.29 \%$ of the variance and included: the distance between the first fully developed leaf and the central flower-head, the main stem diameter, central flower-head diameter, receptacle diameter, and central flower-head weight. The third factor $(8.48 \%$ of variance) entailed the number of lateral shoots, total number of flower-heads, and weight of the heads.

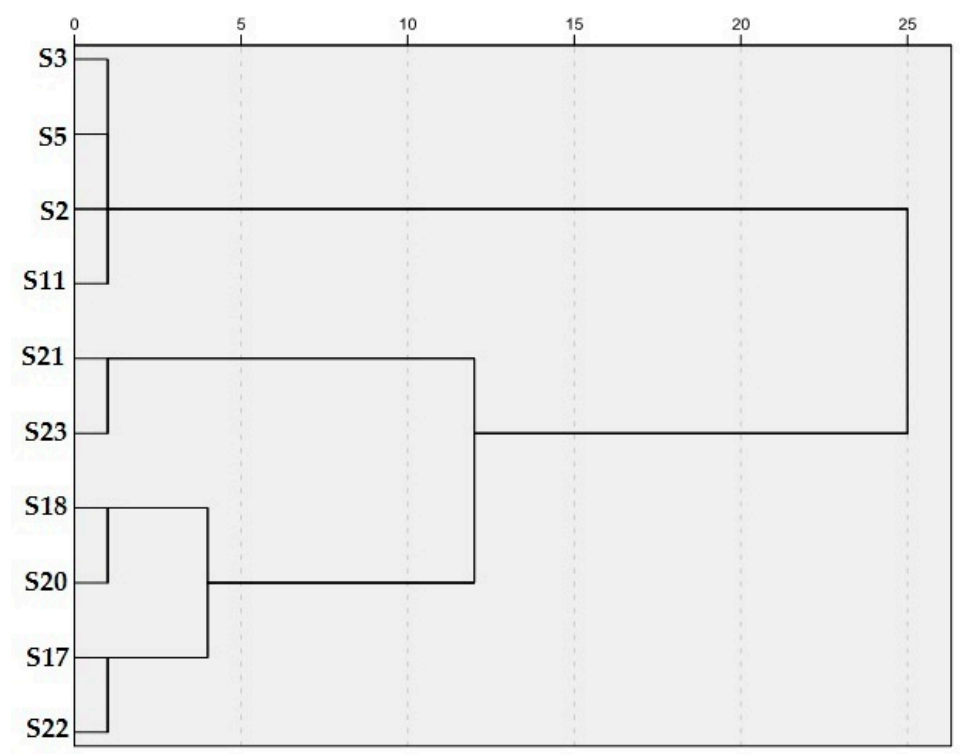

Figure 2. Similarity dendrogram of globe artichoke clones based on an agglomerative hierarchical cluster analysis of the morphological data listed in Table 1. The axis reports the Rescaled Distance Cluster Combine, as from the SPSS output.

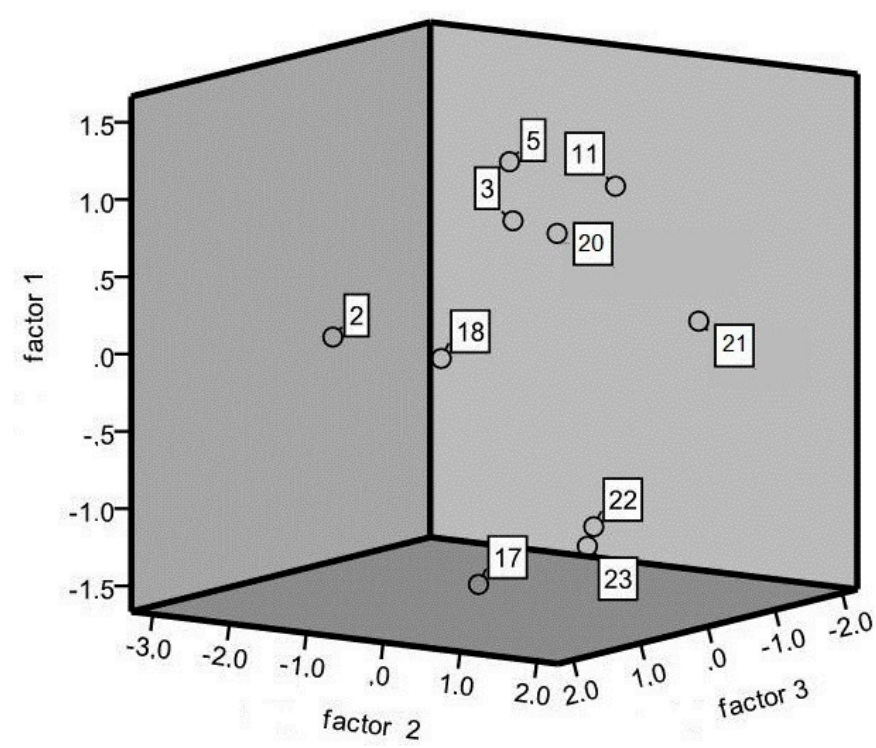

Figure 3. Distribution of the analyzed genotypes against the first three Principal Component functions. 
Table 3. Differences in some morphological traits (means over two years) of the 10 Romanesco landraces analyzed. Plant height (PH, $\mathrm{cm}$ ), distance between the youngest leaf on the main floral stem and the central flower-head (DHL, cm), stem diameter (MSD, cm), head length (HeadL, cm), head diameter (HeadD, cm), head shape (ShapeIndex), head tip shape (ShapeTip), bract colour (ColBract), diameter of the receptacle (RecD, cm), receptacle thickness (RecThick, cm), receptacle shape (RecShape), head weight (HeadW g), time of head maturity (TimeHead), total head number (HeadN), and total head weight (TotHeadW, g)

\begin{tabular}{|c|c|c|c|c|c|c|c|c|c|c|c|c|c|c|c|}
\hline Clones & PH & DHL & MSD & HeadL & HeadD & ShapeIndex & ShapeTip & ColBract & RecD & RecThick & RecShape & HeadW & TimeHead & HeadN & TotHeadW \\
\hline S2 & $68.6^{\mathrm{d}, \mathrm{e}}$ & $23.4^{b, c}$ & $2.80^{a, b}$ & $7.72^{b, c}$ & $9.93^{a, b}$ & $0.78^{\mathrm{e}}$ & $3.54^{\mathrm{a}}$ & $3.00^{b, c}$ & $4.88^{\mathrm{a}}$ & $0.69^{b, c}$ & $1.96^{\mathrm{c}, \mathrm{d}}$ & $358.4^{\mathrm{a}, \mathrm{b}}$ & $191.5^{\mathrm{a}}$ & $8.08^{\mathrm{d}}$ & $1291.7^{\mathrm{e}}$ \\
\hline S3 & $71.4^{\mathrm{c}, \mathrm{d}}$ & $29.6^{a, b}$ & $2.66^{b, c}$ & $8.34^{\mathrm{a}, \mathrm{b}}$ & $9.38^{b, c}$ & $0.89^{a, c}$ & $2.54^{b, d}$ & $3.08^{b, c}$ & $4.20^{\mathrm{a}, \mathrm{b}}$ & $0.57^{c}$ & $2.29^{a, c}$ & $326.8^{a, b}$ & $186.5^{\mathrm{a}}$ & $10.67^{a, d}$ & $1342.1^{\mathrm{e}}$ \\
\hline S5 & $85.1^{a, b}$ & $27.5^{b, c}$ & $2.54^{c}$ & $8.52^{a, b}$ & $9.47 \mathrm{a}, \mathrm{c}$ & $0.90^{\mathrm{a}, \mathrm{b}}$ & $2.46^{c, d}$ & $2.67^{c, d}$ & $4.62^{a, b}$ & $0.61^{\mathrm{c}}$ & $2.61^{\mathrm{a}}$ & $340.3^{a, b}$ & $188.6^{a}$ & $9.5^{b, d}$ & $1323.8^{\mathrm{e}}$ \\
\hline S11 & $79.8^{b, c}$ & $29.5^{a, b}$ & $2.75^{a, c}$ & $8.48^{a, b}$ & $9.51^{a, c}$ & $0.89 \mathrm{a}, \mathrm{c}$ & $1.67^{\mathrm{e}}$ & $3.67 \mathrm{a}, \mathrm{b}$ & $4.38^{\mathrm{a}, \mathrm{b}}$ & $0.64^{c}$ & $2.54^{\mathrm{a}, \mathrm{b}}$ & $354.6^{\mathrm{a}, \mathrm{b}}$ & $188.7^{\mathrm{a}}$ & $10.88^{\mathrm{a}, \mathrm{d}}$ & $1399.0^{\mathrm{d}, \mathrm{e}}$ \\
\hline S17 & $54.1^{\mathrm{f}}$ & $25.2^{b, c}$ & $2.93^{a}$ & $7.28^{c}$ & $9.13^{b, c}$ & $0.80^{\mathrm{b}, \mathrm{e}}$ & $3.38^{\mathrm{a}}$ & $2.25^{\mathrm{d}}$ & $4.68^{\mathrm{a}, \mathrm{b}}$ & $0.90^{\mathrm{a}, \mathrm{b}}$ & $1.13^{\mathrm{e}}$ & $336.9^{\mathrm{a}, \mathrm{b}}$ & $148.7^{\mathrm{e}}$ & $10.58^{\mathrm{a}, \mathrm{d}}$ & $1820.8^{\mathrm{a}, \mathrm{d}}$ \\
\hline S18 & $86.4^{\mathrm{a}, \mathrm{b}}$ & $35.0^{\mathrm{a}}$ & $2.94^{\mathrm{a}}$ & $7.86^{a, c}$ & $9.33^{b, c}$ & $0.84^{\mathrm{a}, \mathrm{d}}$ & $2.96^{\mathrm{a}, \mathrm{d}}$ & $3.50^{a, b}$ & $4.85^{\mathrm{a}}$ & $0.64^{\mathrm{c}}$ & $1.58^{\mathrm{d}, \mathrm{e}}$ & $355.2^{a, b}$ & $183.0^{\mathrm{a}, \mathrm{b}}$ & $9.21^{\mathrm{c}, \mathrm{d}}$ & $1687.1^{\mathrm{b}, \mathrm{e}}$ \\
\hline S20 & $90.7^{\mathrm{a}}$ & $34.6^{\mathrm{a}}$ & $2.61^{b, c}$ & $8.21^{a, c}$ & $8.79^{c}$ & $0.93^{\mathrm{a}}$ & $3.00^{a, c}$ & $3.21 \mathrm{~b}, \mathrm{c}$ & $4.01^{\mathrm{b}}$ & $0.60^{\mathrm{c}}$ & $2.13^{b, c}$ & $314.2^{\mathrm{b}}$ & $183.5^{a, b}$ & $11.38^{a, c}$ & $1647.6^{\mathrm{ce}}$ \\
\hline $\mathrm{S} 21$ & $72.0^{\mathrm{c}, \mathrm{d}}$ & $29.4^{a, b}$ & $2.64^{b, c}$ & $8.76^{\mathrm{a}}$ & $9.91^{\mathrm{a}, \mathrm{b}}$ & $0.88^{a, c}$ & $2.33^{\mathrm{d}}$ & $3.92^{\mathrm{a}}$ & $4.31^{\mathrm{a}, \mathrm{b}}$ & $0.78^{a, c}$ & $1.96^{\mathrm{c}, \mathrm{d}}$ & $378.4^{\mathrm{a}}$ & $175.1^{b, c}$ & $12.50^{a, b}$ & $2174.0^{\mathrm{a}}$ \\
\hline S22 & $59.9^{e, f}$ & $23.1^{b, c}$ & $2.97^{\mathrm{a}}$ & $8.09 \mathrm{a}, \mathrm{c}$ & $10.32^{a}$ & $0.78^{\mathrm{e}}$ & $3.08^{a, c}$ & $2.58^{\mathrm{c}, \mathrm{d}}$ & $4.89^{\mathrm{a}}$ & $0.94^{\mathrm{a}}$ & $1.58^{\mathrm{d}, \mathrm{e}}$ & $359.1^{a, b}$ & $166.1^{\mathrm{c}, \mathrm{d}}$ & $13.54^{\mathrm{a}}$ & $1908.1^{a, c}$ \\
\hline $\mathrm{S} 23$ & $54.2^{\mathrm{f}}$ & $21.3^{c}$ & $2.85^{\mathrm{a}, \mathrm{b}}$ & $7.65^{b, c}$ & $9.61^{a, c}$ & $0.79^{\mathrm{c}, \mathrm{e}}$ & $3.17^{a, b}$ & $2.54^{c, d}$ & $4.80^{\mathrm{a}}$ & $0.99^{\mathrm{a}}$ & $1.58^{\mathrm{d}, \mathrm{e}}$ & $329.9^{a, b}$ & $161.8^{\mathrm{d}}$ & $13.42^{\mathrm{a}}$ & $2107.0^{a, b}$ \\
\hline Std.Er. & 1.62 & 1.44 & 0.39 & 0.20 & 0.18 & 0.02 & 0.14 & 0.13 & 0.14 & 0.04 & 0.09 & 13.68 & 2.082 & 0.596 & 89.719 \\
\hline Y & $* * *$ & $* * *$ & $* * *$ & $* *$ & $* *$ & $* * *$ & $\mathrm{~ns}$ & $* * *$ & ns & $* * * *$ & $* * *$ & $* * *$ & $* * *$ & $* * *$ & $* * *$ \\
\hline $\mathrm{CxY}$ & $* * *$ & $* * *$ & ns & ns & $* * *$ & ns & ns & $* * *$ & ns & $* * *$ & $* *$ & ns & $* * *$ & * & ns \\
\hline
\end{tabular}

Different letters indicate statistically significant differences among clones at $p \leq 0.05$ (ANOVA analysis, Tukey test); ${ }^{*}{ }^{* *}$, and ${ }^{* * *}$ indicate significant differences at $p \leq 0.05, p \leq 0.01$, and $p$ $\leq 0.001$, respectively, and ns stands for non-significant. 


\subsection{DNA Marker Characterization}

The molecular markers of the primers used, differed in their ability to detect genetic variation, as shown by the differences in the number of bands, genetic diversity (He), and PIC (Table 2). This was also found within the same marker type: the ISSR 827 marker detected the highest genetic diversity, whereas ISSR 841 amplified the lowest one; the EcoACG/MseCTT primer pair showed the highest genetic diversity, whereas the MseAC/PstCG, in spite of the high number of bands, had the lowest He value. The most informative SSR marker was CMAL24, with the highest genetic diversity and the highest PIC value, while the least informative were CMAL108, CsPal02, and CsCiCaCa05, with a PIC of only 0.091 .

The number of private alleles for each population ranged from four in S11, to 41 in S20 (Table 4).

Table 4. Private alleles present in each of the clones analyzed.

\begin{tabular}{|c|c|c|}
\hline Clones & N. Private Alleles & Private Bands \\
\hline S11 & 4 & $\mathrm{MgcPca} / 10, \mathrm{MgcPca} / 202,841 / 302,857 / 168$ \\
\hline S17 & 7 & $\begin{array}{l}\mathrm{MacPca} / 107, \mathrm{MgcPca} / 131, \mathrm{MgcPca} / 159, \mathrm{MgcPca} / 228, \mathrm{MgcPca} / 267 \\
\mathrm{MgcPcg} / 9,857 / 277\end{array}$ \\
\hline $\mathrm{S} 18$ & 6 & $\begin{array}{l}\mathrm{MacPcg} / 4, \mathrm{MacPca} / 12, \mathrm{MacPca} / 54, \mathrm{MacPca} / 150, \mathrm{MacPcg} / 24, \mathrm{MacPcg} / 63, \\
\mathrm{MacPcg} / 86, \mathrm{MgcPca} / 30, \mathrm{MgcPca} / 39, \mathrm{MgcPca} / 43, \mathrm{MgcPca} / 60, \mathrm{MgcPca} / 180, \\
\mathrm{MgcPcg} / 3, \mathrm{MgcPcg} / 22, \mathrm{MgcPcg} / 35, \mathrm{MgcPcg} / 151\end{array}$ \\
\hline S2 & 9 & $\begin{array}{l}\text { 810/4, 857/172, MacPca/24, MacPcg/95, MacPcg/228, MgcPca/5, } \\
\mathrm{MgcPca} / 73, \mathrm{MgcPcg} / 15, \mathrm{MgcPcg} / 94\end{array}$ \\
\hline S22 & 20 & $\begin{array}{l}\mathrm{MacPca} / 50, \mathrm{MacPca} / 32, \mathrm{MacPca} / 167, \mathrm{MacPca} / 194, \mathrm{MacPca} / 215, \\
\mathrm{MacPca} / 236, \mathrm{MacPca} / 238, \mathrm{MacPcg} / 16, \mathrm{MacPcg} / 48, \mathrm{MacPcg} / 137, \mathrm{MgcPca} / 4, \\
\mathrm{MgcPca} / 80, \mathrm{MgcPca} / 87, \mathrm{MgcPca} / 107, \mathrm{MgcPca} / 201, \mathrm{MgcPca} / 252, \\
\mathrm{MgcPcg} / 8, \mathrm{MgcPcg} / 105, \mathrm{MgcPcg} / 122, \mathrm{MgcPcg} / 126\end{array}$ \\
\hline $\mathrm{S} 23$ & 8 & $\begin{array}{l}\mathrm{MacPca} / 275, \mathrm{MacPcg} / 115, \mathrm{MgcPca} / 68, \mathrm{MgcPca} / 268, \mathrm{MgcPcg} / 31 \\
\mathrm{MgcPcg} / 82,857 / 41,857 / 191\end{array}$ \\
\hline S3 & 15 & $\begin{array}{l}\mathrm{MacPcg} / 23, \mathrm{MgcPcg} / 26, \mathrm{MacPcg} / 234, \mathrm{MgcPca} / 78, \mathrm{MgcPcg} / 17, \mathrm{MgcPcg} / 20, \\
\mathrm{MgcPcg} / 48, \mathrm{EaccMcta} / 91,810 / 5,841 / 32,841 / 34,841 / 220,841 / 223, \\
857 / 74,857 / 76\end{array}$ \\
\hline S5 & 14 & $\begin{array}{l}\mathrm{MacPca} / 70, \mathrm{MacPca} / 133, \mathrm{MacPca} / 134, \mathrm{MgcPca} / 117, \mathrm{MacPca} / 222 \\
\mathrm{MgcPcg} / 154, \mathrm{MgcPcg} / 167,841 / 51,841 / 53,841 / 131,857 / 62,857 / 193 \\
857 / 262,857 / 275\end{array}$ \\
\hline S21 & 20 & $\begin{array}{l}\text { 841/76, 841/194, 841/195, 841/330, 857/315, 857/321, 857/323, MacPcg/26, } \\
\mathrm{MacPcg} / 37, \mathrm{MacPcg} / 179, \mathrm{MgcPca} / 27, \mathrm{MgcPca} / 32, \mathrm{MgcPca} / 41, \mathrm{MgcPca} / 75, \\
\mathrm{MgcPca} / 133, \mathrm{MgcPca} / 193, \mathrm{MgcPca} / 240, \mathrm{MgcPcg} / 40, \\
\mathrm{MgcPcg} / 138, \mathrm{MgcPcg} / 191\end{array}$ \\
\hline S20 & 37 & 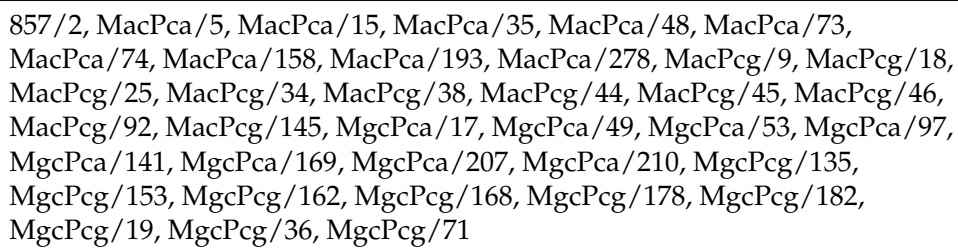 \\
\hline
\end{tabular}

The UPGMA diagram based on Nei's genetic distance between clones, obtained with both dominant and co-dominant DNA markers, is shown in Figure 4. The dendrogram revealed three clusters: a first tight group with S3, S5 (late from south Rome), S17 and S18 (from the C3 selection); a second group with S2, S11, and S23; and a third group with S20, S21, and S22, highlighting distinct and separate genotypes. Hence, Figure 4 reflects only part of the agro-morphological differences among Romanesco clones (also shown in Figure 2). In particular, S22 and S20, belonging to the third group, showed similar head yields and number of lateral shoots. In contrast, S2 and S11 were grouped as late-maturing clones, according to the time of the appearance of the central flower-head and by the growing/collecting area. 


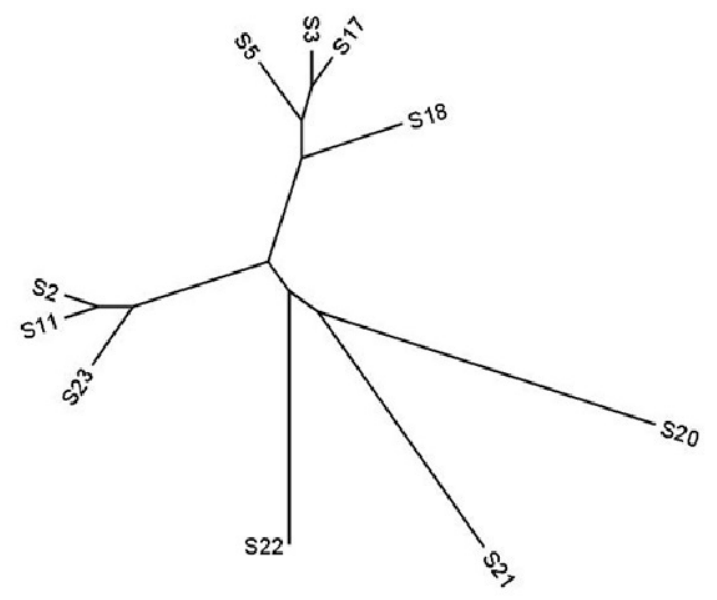

Figure 4. UPGMA dendrogram of the Nei's genetic distance among 10 clones obtained with dominant and co-dominant molecular markers.

A significant correlation between genetic similarity and morphological trait matrices was illustrated by the Mantel test result $(r=-0.29279$; at $p \leq 0.05)$.

\subsection{Biochemical Characterization}

Polyphenol profiles, determined by HPLC analysis, of the primary flower-heads of the 10 Romanesco clones, are given in Table 5 . The biocompounds cynarin, apigenin, and luteolin, were not detected in any of the samples analyzed. However, statistical differences among genotypes were found under the biochemical profile of the heads, when assessing other biocompounds. In particular, $\mathrm{S} 3$ and S5 clones were found to contain the highest content of 1,5-O-dicaffeoylquinic acid. These clones, in addition to S21, S2, S17, S18, and S22, were also characterized by the highest content of chlorogenic acid. S5 and S23 clones contained the highest levels of cynaroside, (Table 5). S2, S3, S5, and S18 clones showed values of the total polyphenols measured: $13.84,14.01,15.27$, and $14.20 \mathrm{~g} \mathrm{~kg}^{-1} \mathrm{DM}$, respectively. The Mantel test results of the biochemical and morphological trait matrices showed a slightly positive significant correlation between the lateness of genotype production and the 1,5-O-dicaffeoylquinic acid content (Pearson's correlation coefficient $r=0.646, p \leq 0.05$ ).

Table 5. Biochemical characterization (in $\mathrm{g} \cdot \mathrm{kg}^{-1} \mathrm{DM}$ ) of the heads of the 10 Romanesco clones.

\begin{tabular}{cccccc}
\hline Clones & $\begin{array}{c}\text { 1,5-O-Dicaffeoylquinic } \\
\text { Acid }\end{array}$ & $\begin{array}{c}\text { Chlorogenic } \\
\text { Acid }\end{array}$ & Cynaroside & $\begin{array}{c}\text { Total } \\
\text { Caffeolyquinic } \\
\text { Acids }\end{array}$ & $\begin{array}{c}\text { Total } \\
\text { Measured } \\
\text { Polyphenols }\end{array}$ \\
\hline S20 & $4.17^{\mathrm{d}}$ & $3.62^{\mathrm{d}}$ & $0.46^{\mathrm{b}}$ & $7.79^{\mathrm{e}}$ & $8.25^{\mathrm{e}}$ \\
S21 & $5.99^{\mathrm{c}}$ & $6.52^{\mathrm{a}, \mathrm{b}}$ & $0.34^{\mathrm{c}, \mathrm{d}}$ & $12.51^{\mathrm{b}, \mathrm{c}}$ & $12.85^{\mathrm{b}, \mathrm{c}}$ \\
S2 & $6.44^{\mathrm{b}, \mathrm{c}}$ & $7.00^{\mathrm{a}}$ & $0.40^{\mathrm{b}, \mathrm{c}}$ & $13.44^{\mathrm{a}, \mathrm{b}}$ & $13.84^{\mathrm{a}, \mathrm{b}}$ \\
S3 & $7.05^{\mathrm{a}, \mathrm{b}}$ & $6.74^{\mathrm{a}}$ & $0.31^{\mathrm{d}}$ & $13.79^{\mathrm{a}, \mathrm{b}}$ & $14.01^{\mathrm{a}, \mathrm{b}}$ \\
S5 & $7.38^{\mathrm{a}}$ & $7.30^{\mathrm{a}}$ & $0.59^{\mathrm{a}}$ & $14.68^{\mathrm{a}}$ & $15.27^{\mathrm{a}}$ \\
S11 & $5.96^{\mathrm{c}}$ & $5.93^{\mathrm{b}}$ & $0.43^{\mathrm{b}}$ & $11.89^{\mathrm{c}}$ & $12.32^{\mathrm{c}}$ \\
S17 & $3.49^{\mathrm{e}}$ & $6.63^{\mathrm{a}, \mathrm{b}}$ & $0.42^{\mathrm{b}, \mathrm{c}}$ & $10.12^{\mathrm{d}}$ & $10.54^{\mathrm{d}}$ \\
S18 & $6.60^{\mathrm{b}, \mathrm{c}}$ & $7.32^{\mathrm{a}}$ & $0.28^{\mathrm{d}}$ & $13.92^{\mathrm{a}, \mathrm{b}}$ & $14.20^{\mathrm{a}, \mathrm{b}}$ \\
S22 & $4.93^{\mathrm{e}}$ & $6.69^{\mathrm{a}, \mathrm{b}}$ & $0.41^{\mathrm{b}, \mathrm{c}}$ & $11.62^{\mathrm{c}}$ & $12.03^{\mathrm{c}}$ \\
S23 & $3.53^{\mathrm{e}}$ & $4.42^{\mathrm{c}}$ & $0.55^{\mathrm{a}}$ & $7.95^{\mathrm{e}}$ & $8.50^{\mathrm{e}}$ \\
Std. Error & $0.265^{\mathrm{e}}$ & 0.266 & 0.030 & $0.527^{2}$ & 0.535 \\
\hline Different letters indicate statistically significant differences among clones at $p \leq 0.05$ (ANOVA analysis, Tukey test).
\end{tabular}

\section{Discussion}

This study characterized 10 autochthonous clones of Romanesco type through assessing a combination of morphological, biochemical, and molecular traits. This complementarity was used 
successfully, to provide more robust and reliable data than those obtained based on a single technique, as previously observed by other authors $[2,19,20,34]$.

The agro-morphological assessment, undertaken using UPOV descriptors, revealed significant differences among clones for 15 of the 47 quantitative and qualitative traits measured. It is not surprising that traits such as spines, color, or lobes, did not vary among clones of the Romanesco typology. Nevertheless, as with previous observations [18,22], most of the morphological quantitative traits exhibited significant clone-by-year interactions, implying a strong environmental basis for these traits; thus highlighting a weakness of some of the descriptors used as universal standards [23]. In addition, as evidenced by ANOVA analysis (Table 3), significant differences were detected between years for most of the quantitative and qualitative traits assessed.

Nevertheless, particular traits, such as plant height, head shape index, receptacle shape, head yield, and earliness, as observed in preliminary trials [18], differentiated the Romanesco clones. These characteristics could, therefore, be useful for clone selection. Another trait is the distance between the youngest leaf on the main floral stem and the central flower-head (S3, S11, S18, S20, S21), which could be a suitable trait for mechanical head harvesting.

On the basis of the morphological evaluations, S17 and S22 showed agronomic profiles with useful values of earliness and production (number of heads and weight). As these data confirmed results previously obtained [18], these clones were submitted to the Italian Ministry of Agriculture to be included on the National Variety Register, with the names Michelangelo and Raffaello, respectively. These varieties have been accepted by the Italian Ministry of Agriculture, Food and Forestry Policies with Decree no. 6135 of 29 March 2013, and published in the Official Journal no. 91 of 18 April 2013.

The clones grouped into two main clusters on the basis of morphological traits were congruent with the agro-morphological traits observed, and reflected the geographical origin of the germplasm. In contrast, the grouping clusters based on molecular data did not show the same level of congruence. Mauro et al. [21] have observed that a likely cause of this is due to most of the AFLP loci being located in non-coding portions of the genome and, therefore, they have little or no link to the phenotype. Moreover, molecular analyses included assessments of allelic richness, the presence of private alleles, and the frequency of 'locally common' alleles in a population; all of which are informative and useful for the management of on-farm germplasm. In particular, the identification of unique alleles in a population allows the possibility of using clone-specific fragments for a simple PCR-based test of clone identity.

In this study, molecular analyses did not discriminate clones as early or late types, diverging from the findings made by Lanteri et al. [35], who found a positive correlation between earliness and accession cluster grouping. However, this discrepancy may depend on the fact that the clones analyzed in our study were of the same Romanesco typology.

Marker-assisted selection remains untested in the globe artichoke, since the genome has only recently been sequenced [36], and the associations between bands and traits need to be tested over several years and environments. However, molecular data from this study has described markers useful for discriminating clones and assessing their genetic diversity. All clones have been clearly distinguished from each other through the assessment of genetic diversity. The germplasm exhibited high levels of polymorphism and reproducibility, as reported by other authors $[18,30,37]$. The SSR markers' ability to detect polymorphisms, as revealed by the PIC values, are only partially in agreement with the results of Pagnotta et al. [30] who, in collaboration with partners, undertook analyses of all European holdings of global artichoke. They undertook assessments of typologies other than only Romanesco. The markers CMAL11, CMAL117, CMAL24, CMAL06, CLIB-12, CMAFLP18, CsPal03, and CsEST03, exhibited similar values in both studies, whereas CMAL-108 and CsPal02 exhibited much lower values in this study. Of all the markers, the SSR marker CsCiCaCa05 was found to be the least informative one.

One of the aims of this study was also to characterize the germplasm under its biochemical profile, for assessing the most promising clones for marketing as fresh market vegetables or for 
industrial purposes. In accordance with Pandino et al. [38,39], chlorogenic acid, 1,5-O-dicaffeoylquinic acid, and cynaroside, were found to be the most representative compounds. In contrast, the flavonoids, luteolin, and apigenin, were not detected within samples in this study; this could depend on the different extraction techniques used or/and on the genotype. However, the results so far obtained showed that clones exhibited different polyphenolic profiles, acquired from the capitula, as has also been observed by other authors who biochemically characterized several globe artichoke genotypes [40,41]. Further plant breeding programs could focus on selecting genotypes as sources of particular biochemical compounds. In particular, some late clones such as S2, S5, S3, and S18, were very rich in polyphenols and this trait could lend to their suitability for markets. Indeed, the consumption of polyphenols has been reported to have hepatoprotective, anticarcinogenic, antioxidative, antibacterial, urinative, anticholesterol, and antiglycaemic effects [42-45]. Other clones (i.e., S20 and S23), characterized by a low polyphenol content, could be used for industrial processing. In fact, as reported by Lattanzio et al. [46], the browning phenomena, caused by polyphenol oxidation due to polyphenoloxidase, could be addressed by selecting clones with a low polyphenol content.

The high levels of diversity detected using morphological, biochemical, and molecular analyses, together with the possibility of distinguishing among clones, opens up options for developing targeted breeding programs for varietal release. It is essential to conserve, characterize, and evaluate this germplasm in ex-situ facilities.

It is also critical to assess and preserve the variation present within farmer's fields and develop in-situ on-farm conservation strategies, with clear links to ex-situ conservation programs. A well-conceived conservation strategy could address the genetic erosion, currently driven by the widespread cultivation of the micropropagated clone C3.

Despite the high levels of variation found within populations, most populations can be genetically differentiated from one another [21]. Portis et al. [13] suggested that this might be a consequence of farm fragmentation, together with the limited exchange of materials between individual farmers.

\section{Conclusions}

The work undertaken has resulted in two clones, named S17 and S22, being released as early varieties and registered under the names of Michelangelo and Raffaello, respectively, in collaboration with ARSIAL (Latium Regional Agency for the Development and the Innovation of Agriculture). These two clones represent the first vegetatively propagated materials released in Italy.

These efforts highlight the need for the assessment of this traditional germplasm under different profiles, fundamental for its protection and conservation. The value of plant genetic resources lies in producing new cultivars, and in responding to new challenges based on systems of sustainable production and improved nutritional quality [34,40].

Acknowledgments: The authors acknowledge the "CYNARES" project for financial support, sponsored by the AGRI GEN RES Community Programme (European Commission, Directorate-General for Agriculture and Rural Development, under Council Regulation (EC) No. 870/2004). Authors acknowledge Arshiya Noorani for useful comments and manuscript revision.

Author Contributions: M.A.P. and P.C. conceived, designed, and performed the experiment, and analyzed the data; M.A.P. wrote the paper.

Conflicts of Interest: The authors declare no conflict of interest. The founding sponsors had no role in the design of the study; in the collection, analyses, or interpretation of data; in the writing of the manuscript; and in the decision to publish the results.

\section{References}

1. Bianco, V.V. Carciofo (Cynara scolymus). In Orticoltura; Orticoltura Bianco, V.V., Rimpini, F., Eds.; Patron Editore: Bologna, Italy, 1990; pp. 209-251. 
2. Mauro, R.; Portis, E.; Acquadro, A.; Lombardo, S.; Mauromicale, G.; Lanteri, S. Genetic diversity of globe artichoke landraces from Sicilian small-holdings: Implications for evolution and domestication of the species. Conserv. Genet. 2009, 10, 431-440. [CrossRef]

3. Ierna, A.; Mauro, R.P.; Mauromicale, G. Biomass, grain and Energy yield in Cynara cardunculus L. as affected by fertilization, genotype and harvest time. Biomass Bioenergy 2012, 36, 404-410. [CrossRef]

4. Ledda, L.; Deligios, P.A.; Farci, R.; Sulas, L. Biomass supply for energetic purposes from some Cardueae species grown in Mediterranean farming systems. Ind. Crops Prod. 2013, 47, 218-226. [CrossRef]

5. Lombardo, S.; Pandino, G.; Ierna, A.; Mauromicale, G. Variation of polyphenols in a germplasm collection of globe artichoke. Food Res. Int. 2012, 46, 544-553. [CrossRef]

6. Ciancolini, A.; Alignan, M.; Pagnotta, M.A.; Miquel, J.; Vilarem, G.; Crinò, P. Morphological characterization, biomass and pharmaceutical compounds in Italian globe artichoke genotypes. Ind. Crops Prod. 2013, 49, 326-333. [CrossRef]

7. FAOSTAT Data 2013. Available online: http://www.fao.org/faostat/en/\#data (accessed on 30 October 2016).

8. ISTAT (Italian National Institute of Statistics) 2009. Available online: http://dati.istat.it/Index.aspx? DataSetCode=DCSP_COLTIVAZ\&Lang=en (accessed on 25 October 2016).

9. Pignone, D.; Sonnante, G. Wild artichokes of south Italy: Did the story begin here? Genet. Resour. Crop Evol. 2004, 51, 577-580. [CrossRef]

10. Porceddu, E.; Dellacecca, V.; Blanco, V.V. Classificazione numerica di cultivar di carciofo. In Proceedings of the II International Congress of Artichoke, Bari, Italy, 17-21 October 1976; pp. 1105-1119.

11. Mauromicale, G.; Ierna, A. Characteristics of heads of seed-grown globe artichoke [Cynara cardunculus L. var. scolymus (L.) Fiori] as affected by harvest period, sowing date and gibberellic acid. Agronomie 2000, 20, 197-204.

12. Acquadro, A.; Papanice, M.A.; Lanteri, S.; Bottalico, G.; Portis, E.; Campanale, A.; Finetti-Sialer, M.M.; Mascia, T.; Sumerano, P.; Gallitelli, D. Production and fingerprinting of virus-free clones in a reflowering globe artichoke. Plant Cell Tissue Organ Cult. 2010, 100, 329-337. [CrossRef]

13. Portis, E.; Mauromicale, G.; Barchi, L.; Mauro, R.; Lanteri, S. Population structure and genetic variation in autochthonous globe artichoke germplasm from Sicily Island. Plant Sci. 2005, 168, 1591-1598. [CrossRef]

14. Bonasia, A.; Conversa, G.; Lazzizera, C.; Gambacorta, G.; Elia, A. Morphological and qualitative characterisation of globe artichoke head from new seed-propagated cultivars. J. Sci. Food Agric. 2010, 90, 2689-2693. [CrossRef] [PubMed]

15. Soressi, G. Available variability usable for breeding of globe artichoke [Cynara cardunculus L. var. scolymus L.]. Inf Agrar. 2003, 22, 47.

16. Ancora, G.; Crinò, P.; Tavazza, R.; Pagnotta, M.A.; Temperini, O.; Campanelli, R.; Saccardo, F. The first three clones selected from the traditional artichoke Romanesco populations and proposed for the release of new varieties. Acta Horticult. 2012, 942, 125-132. [CrossRef]

17. De Vos, N.E. Artichoke production in California. HortTechnology 1992, 2, 438-444.

18. Crinò, P.; Tavazza, R.; Rey Muñoz, N.A.; Trionfetti Nisini, P.; Saccardo, F.; Ancora, G.; Pagnotta, M.A. Recovery, morphological and molecular characterisation of globe artichoke 'Romanesco' landraces. Genet. Resour. Crop Evol. 2008, 55, 823-833. [CrossRef]

19. Cappelletti, R.; Mezzetti, B.; Balducci, F.; Diamanti, J.; Capocasa, F. Morphological, nutraceutical and chemical characterization of globe artichoke (Cynara cardunculus L. var. scolymus (L.) Fiori) landraces typically cultivated in Marche area. Acta Hortic. 2013, 983, 39-46. [CrossRef]

20. Mauro, R.; Portis, E.; Lanteri, S.; Mauromicale, G. Genotypic and bio-agronomical characterization of an early Sicilian landrace of globe artichoke. Euphytica 2012, 186, 357-366. [CrossRef]

21. Mauro, R.; Portis, E.; Lanteri, S.; Mauromicale, G. Bio-agronomical and molecular characterization of selected clones in the early Sicilian globe artichoke landrace 'violetto di Sicilia'. Acta Horticult. 2013, 983, $209-214$. [CrossRef]

22. Ciancolini, A.; Rey, N.A.; Pagnotta, M.A.; Crinò, P. Characterization of Italian spring globe artichoke germplasm: morphological and molecular profiles. Euphytica 2012, 186, 433-443. [CrossRef]

23. Pagnotta, M.A.; Rey, N.A.; Ciancolini, A.; Crinò, P. Are UPOV Descriptors a Useful and Feasible Tool? Acta Hort. 2013, 983, 145-149. [CrossRef] 
24. Vos, P.; Hogers, R.; Bleeker, M.; Reijand, M.; Van de Lee, T.; Hornes, M.; Fritjers, A.; Pot, J.; Paleman, J.; Kuiper, M.; et al. AFLP: A new technique for DNA fingerprinting. Nucleic Acids Res. 1995, 23, 4407-4414. [CrossRef] [PubMed]

25. Acquadro, A.; Portis, E.; Lee, D.; Donini, P.; Lanteri, S. Development and characterization of microsatellite markers in Cynara cardunculus L. Genome 2005, 48, 217-225. [CrossRef] [PubMed]

26. Acquadro, A.; Portis, E.; Lanteri, S. Isolation of microsatellite loci in artichoke (Cynara cardunculus L. var. scolymus). Mol. Ecol. Notes 2003, 3, 37-39. [CrossRef]

27. Acquadro, A.; Portis, E.; Albertini, E.; Lanteri, S. M-AFLP-based protocol for microsatellite loci isolation in Cynara cardunculus L. (Asteraceae). Mol. Ecol. Notes 2005, 5, 272-274. [CrossRef]

28. Sonnante, G.; Carluccio, A.V.; De Paolis, A.; Pignone, D. Identification of artichoke SSR markers: Molecular variation and patterns of diversity in genetically cohesive taxa and wild allies. Genet. Resour. Crop Evol. 2008, 55, 1029-1046. [CrossRef]

29. Pagnotta, M.A.; Fernández, J.A.; Sonnante, G.; Egea Gilabert, C. Genetic diversity and accession structure in European Cynara cardunculus collections. 2017. (in press)

30. Peakall, R.; Smouse, P.E. GenAlEx 6.5: Genetic analysis in Excel. Population genetic software for teaching and research-an update. Bioinformatics 2012, 28, 2537-2539. [CrossRef] [PubMed]

31. Liu, K.; Muse, S.V. PowerMarker: An integrated analysis environment for genetic marker analysis. Bioinformatics 2005, 21, 2128-2129. [CrossRef] [PubMed]

32. Nei, M. Genetic distance between populations. Am. Nat. 1972, 106, 183-192. [CrossRef]

33. Mantel, N.A. The detection of disease clustering and a generalized regression approach. Cancer Res. 1967, 27, 209-220. [PubMed]

34. Lahoz, I.; Fernández, J.A.; Migliaro, D.; Macua, J.I.; Egea-Gilabert, C. Using molecular markers, nutritional traits and field performance data to characterize cultivated cardoon germplasm resources. Sci. Hortic. 2011, 127, 188-197. [CrossRef]

35. Lanteri, S.; Acquadro, A.; Saba, E.; Portis, E. Molecular fingerprinting and evaluation of genetic distances among selected clones of globe artichoke (Cynara cardunculus L. var. scolymus L.). J. Horticult. Sci. Biotechnol. 2004, 79, 863-870. [CrossRef]

36. Scaglione, D.; Reyes-Chin Who, S.; Acquadro, A.; Froenicke, L.; Portis, E.; Beitel, C.; Tirone, M.; Mauro, R.; Lo Monaco, A.; Mauromicale, G.; et al. The genome sequence of the outbreeding globe artichoke constructed de novo incorporating a phase-aware low-pass sequestrategy of a $\mathrm{F}_{1}$ progeny. Sci. Rep. 2016, 6, 25323. [CrossRef] [PubMed]

37. Lo Bianco, C.L.; Fernández, J.A.; Migliaro, D.; Crinò, P.; Egea-Gilabert, C. Identification of F1 hybrids of artichoke by ISSR markers and morphological analysis. Mol. Breed. 2011, 27, 157-170. [CrossRef]

38. Pandino, G.; Lombardo, S.; Mauro, R.P.; Mauromicale, G. Variation in polyphenol profile and head morphology among clones of globe artichoke selected from a landrace. Sci. Horticult. 2012, 138, 259-265. [CrossRef]

39. Pandino, G.; Lombardo, S.; Mauromicale, G. Globe artichoke leaves and floral stems as a source of bioactive compounds. Ind. Crops Prod. 2013, 44, 44-49. [CrossRef]

40. Lombardo, S.; Pandino, G.; Mauromicale, G.; Knödler, M.; Carle, R.; Schieber, A. Influence of genotype, harvest time and plant part on polyphenolic composition of globe artichoke [Cynara cardunculus L. var. scolymus (L.) Fiori]. Food Chem. 2010, 119, 1175-1181. [CrossRef]

41. Pandino, G.; Lombardo, S.; Mauromicale, G.; Williamson, G. Profile of poyphenols and phenolic acids in bracts and receptacles of globe artichoke (Cynara cardunculus var. scolymus), germplasm. J. Food Compos. Anal. 2011, 24, 148-153. [CrossRef]

42. Rodriguez, T.S.; Giménez, D.G.; De La Puerta Vázquez, R. Choleretic activity and biliary elimination of lipids and bile acids induced by an artichoke leaf extract in rats. Phytomedicine 2002, 9, 687-693. [CrossRef] [PubMed]

43. Coinu, R.; Carta, S.; Urgeghe, P.P.; Mulinacci, N.; Pinelli, P.; Franconi, F.; Romani, A. Dose-effect study on the antioxidant properties of leaves and outer bracts of extracts obtained from Violetto di Toscana artichoke. Food Chem. 2007, 101, 524-531. [CrossRef] 
44. Rondanelli, M.; Giacosa, A.; Opizzi, A.; Faliva, M.A.; Sala, P.; Perna, S.; Bombardelli, E. Beneficial effects of artichoke leaf extract supplementation on increasing HDL-cholesterol in subjects with primary mild hypercholesterolaemia: A double-blind, randomized, placebo-controlled trial. Int. J. Food Sci. Nutr. 2013, 64, 7-15. [CrossRef] [PubMed]

45. Fantini, N.; Colombo, G.; Giori, A.; Riva, A.; Morazzoni, P.; Bombardelli, E.; Carai, M.A. Evidence of glycemia-lowering effect by a Cynara scolymus L. extract in normal and obese rats. Phytother. Res. 2011, 25, 463-466. [CrossRef] [PubMed]

46. Lattanzio, V.; Cardinali, A.; Di Venere, D.; Linsalata, V.; Palmieri, S. Browning phenomena in stored artichoke (Cynara scolymus L.) heads: Enzymic or chemical reactions? Food Chem. 1994, 50, 1-7. [CrossRef]

(C) 2017 by the authors. Licensee MDPI, Basel, Switzerland. This article is an open access article distributed under the terms and conditions of the Creative Commons Attribution (CC BY) license (http:/ / creativecommons.org/licenses/by/4.0/). 